\title{
UDP-GIcNAc2-epimerase regulates cell surface sialylation and ceramide-induced cell death in human malignant lymphoma
}

\author{
OSAMU SUZUKI ${ }^{1}$, KAZUHIRO TASAKI $^{1}$, TAKASHI KUSAKABE $^{2}$ and MASAFUMI ABE ${ }^{1}$ \\ ${ }^{1}$ First Department of Pathology, ${ }^{2}$ Second Department of Pathology, School of Medicine, \\ Fukushima Medical University, Fukushima, Japan
}

Received April 18,2008; Accepted May 28, 2008

DOI: $10.3892 /$ ijmm_00000028

\begin{abstract}
Stress signals induce ceramide (cer) through sphingomyelinase activation, and metabolites of cer such as sphingosine ( $\mathrm{Sph}$ ) and sphingosine-1-phoshate (S-1-P) play a significant role in many biological processes. This study aimed to elucidate the association between the alteration in cell surface sialylation and ceramide-induced cell death in the human Burkitt's lymphoma cell line, HBL-8. The highly sialylated 3G3 clone was less sensitive to C6-ceramideinduced cell death. On the other hand, the hyposialylated 3D2 clone was more sensitive to C6-ceramide-induced cell death. Neuraminidase treatment or knockdown by siRNA of uridine diphosphate- $\mathrm{N}$-acetylglucosamine 2-epimerase (UDP-GlcNAc2-epimerase), which is a key enzyme of sialic acid biosynthesis, enhanced the amount of cell death induced by C6-ceramide in the highly sialylated $3 \mathrm{G} 3$ clone. Sialic acid metabolic complementation assays using several precursors of sialic acid showed that cell surface resialylation by $\mathrm{N}$-acetyl-D-mannosamine (ManNAc) inhibited C6-ceramideinduced cell death. The amount of cell death by C6-ceramide was enhanced after pretreatment with phosphatidylinositol 3kinase (PI3K) inhibitor, LY294002 in both clones. In addition, clone $3 \mathrm{G} 3$ was less sensitive to Sph than the 3D2 clone. In conclusion, in human malignant lymphoma, ceramide and its metabolite-induced cell death is regulated by the amount of sialic acid on the cell surface which in turn is regulated by mRNA expression of UDP-GlcNAc2-epimerase.
\end{abstract}

\section{Introduction}

Sialic acids are important regulators of cellular and molecular interactions. They can either mask recognition sites or serve

Correspondence to: Dr Osamu Suzuki, Fukushima Medical University, School of Medicine, First Department of Pathology, 1 Hikariga-oka, Fukushima 960-1295, Japan

E-mail: osuzuki@fmu.ac.jp

Key words: UDP-GlcNAc2-epimerase, sialylation, ceramide, malignant lymphoma as recognition determinants (1). Sialic acid plays an important role in tumor cell behavior by affecting cell adhesion, invasiveness, and metastasis (2-7), as well as affecting clinical outcomes $(8,9)$ and Fas-induced apoptosis $(10-12)$. Uridine diphosphate-N-acetylglucosamine 2-epimerase (UDPGlcNAc2-epimerase) is a key enzyme in sialic acid biosynthesis (13), and is essential for development in mice (14). Expression of UDP-GlcNAc2-epimerase mRNA was found to correlate with the sialic acid content in a human Burkitt's lymphoma cell line and to regulate the expression of sialoglycoconjugates, which affect the adhesion of Burkitt's lymphoma cells to collagen type IV and fibronectin (15).

Sphingolipids modify the physical properties of cell membranes (16). Ceramide, sphingosine, and Sphingosine-1phosphate (S-1-P) are associated with cell growth arrest and are important regulatory components of stress responses and apoptosis (17). Stress signals produce ceramide $(18,19)$, and ceramide is converted to sphingosine by the activity of ceramidase and subsequently converted to sphingosine-1phosphate by the activity of sphingosine kinase (20) at the cell surface or extracellular milieu (21). Sphingosine induces a rapid necrotic cell death (22).

Cell surface sialylation is reported to modulate the susceptibility to sphingomyelinase and subsequent production of ceramide in a human diffuse large B cell lymphoma cell line (23), as well as regulate sphingolipid-induced cell death in human B cell lymphoma cell lines (24).

In the present study we show that alteration in cell surface sialylation regulates ceramide and its metabolite-induced cell death in a human Burkitt's lymphoma cell line.

\section{Materials and methods}

Cell lines. HBL-8 is a human Burkitt's lymphoma cell line (5). HBL-8 cells were grown at $37^{\circ} \mathrm{C}$ in RPMI-1640 containing $15 \%$ fetal calf serum and in an atmosphere containing $5 \%$ $\mathrm{CO}_{2}$. The two clones of HBL-8 (3G3 and 3D2) show different reactivities to soybean agglutinin (SBA) and Vicia villosa agglutinin (VVA) lectins as well as different metastatic capacities in the severe combined immunodeficiency (SCID) mouse animal model (5). These clones have a different amount of cell surface sialic acid due to differences in the mRNA expression of UDP-GlcNAc2-epimerase, which is a key enzyme in sialic acid biosynthesis (15). Expression of the 
mRNA for ß-galactoside- $\alpha 2,6$-sialyltransferase (ST6Gal I) and Galß(1-3/1-4)GlcNAc- $\alpha 2,3$-sialyltransferase (ST3Gal IV) are detected in both the $3 \mathrm{G} 3$ and 3D2 clones (15).

Antibodies and reagents. Biotinylated Limax flavus agglutinin (LFA) and Maackia amurensis agglutinin (MAA), which are sialic acid-specific lectins, were from EY Laboratories (San Mateo, CA, USA). Neuraminidase from Vibrio cholerae was purchased from Roche (Germany). C6-ceramide were from Sigma (USA). Sphingosine and Sphingosine-1-phosphate were from Biomol (USA). N-acetyl-D-mannosamine (ManNAc), $\mathrm{N}$-acetyl-D-glucosamine, and $\alpha$-D-Mannose (Man) were from Sigma. The caspase inhibitor carbobenzoxy-L-valylß-methyl-L-aspart-1-fluoromethane (z-VAD-fmk) was obtained from Peptide Institute, Inc. (Japan) and was dissolved in dimethyl sulfoxide.

Flow cytometry. HBL-8 cells $\left(5 \times 10^{5}\right.$ cells) were suspended in $100 \mu \mathrm{l}$ of phosphate-buffered saline (PBS) and incubated at $4^{\circ} \mathrm{C}$ for 20 min with $5 \mu 1$ of biotinylated LFA lectins and then washed twice with PBS. Next, the cells were incubated at $4^{\circ} \mathrm{C}$ for $20 \mathrm{~min}$ with $5 \mu \mathrm{l}$ of avidin-fluorescein isothiocyanate (FITC; Vector Laboratories, Inc., Burlingame, CA, USA) and washed twice with PBS. Fluorescent intensities were analyzed on a FACSCalibur (Becton-Dickinson, Mountain View, CA, USA). To analyze cell surface sialylation, $6 \times 10^{6}$ cells were incubated at $37^{\circ} \mathrm{C}$ for $30 \mathrm{~min}$ in $200 \mu \mathrm{l}$ of RPMI-1640 containing $15 \%$ fetal calf serum and $40 \mu \mathrm{l}$ of $1 \mathrm{U} / \mathrm{ml}$ Vibrio cholerae neuraminidase (Boehringer-Mannheim, Germany) before incubation with biotinylated lectins (15).

For the sialic acid metabolic complementation assay, the HBL-8 3D2 clone cells $\left(1 \times 10^{7}\right.$ cells $)$ were incubated with $10 \mathrm{mM}$ ManNAc or Man in $25 \mathrm{ml}$ RPMI-1640 culture medium containing $15 \% \mathrm{FCS}$ for $72 \mathrm{~h}$ at $37^{\circ} \mathrm{C}$. Then the LFA lectin reactivity was analyzed by flow cytometry as previously described.

For analysis by the Annexin-V-FLUOS Staining kit (Roche, Germany), HBL- 8 cells $\left(2 \times 10^{6}\right.$ cells $)$ were suspended in $100 \mu 1$ of incubation buffer (included in the kit) with $2 \mu 1$ Annexin-V-fluorescein and $2 \mu 1$ propidium iodide (PI) at RT for $15 \mathrm{~min}$. After centrifugation, cells were resuspended by sheath flow fluid and analyzed by FACSCalibur.

Transfection of siRNA for UDP-GlcNAc2-epimerase in the $H B L-83 G 3$ clone. In order to analyze the regulatory mechanism of cell surface sialylation by mRNA expression of UDP-GlcNAc2-epimerase, siRNA transfection was performed as described previously with several modifications (25). Cells $\left(1 \times 10^{6}\right) / 500 \mu 1$ in $15 \%$ FCS containing RPMI- 1640 medium were incubated in each well of a 24-well plate. Then $2 \mu 1$ INTERFERin (Polyplus Transfection, USA) reagent was added to $100 \mu \mathrm{l}$ serum-free medium, and $1 \mu \mathrm{l}$ siRNA (sense, GGUUUUUAUGGGUACUUUUtt; antisense, AAAAGUAC CCAUAAAAACCtg, catalogue no. 700, Ambion K.K. Japan) $(50 \mu \mathrm{M}$, final concentration $500 \mathrm{nM})$ and immediately vortexed for $10 \mathrm{~min}$. Then the $100 \mu \mathrm{l}$ serum-free medium containing $500 \mathrm{nM}$ siRNA was added to each well $\left(1 \times 10^{6}\right.$ cells $/ 500 \mu 1$, final concentration of siRNA was $83 \mathrm{nM}$ ). For control experiments, Ambion Silencer ${ }^{\mathrm{TM}}$ negative control siRNA (catalogue no. 4611) was applied. After 48-h incubation, the amount of cell surface sialylation was analyzed by MAA lectin flow cytometry.

Detection of mRNA of UDP-GlcNAc2-epimerase by RT-PCR. Total RNA was extracted from HBL- 8 cell lines using TRIsol (Invitrogen, The Netherlands) according to the manufacturer's instructions. After adding $5 \mu \mathrm{g}$ of total RNA with $1 \mu \mathrm{l}$ of 1000 pmol random primers (Takara Bio) and $1 \mu \mathrm{l}$ of $10 \mathrm{mM}$ dNTP mixture (Takara), reverse transcription was performed using SuperScript III Rnase H-Reverse Transcriptase (Invitrogen, Carlsbad, CA, USA) according to the manufacturer's protocol. Aliquots of cDNA $(1 \mu \mathrm{g})$ were amplified using Takara Ex Taq HS polymerase in a total volume of $50 \mu 1$. For detection of UDP-GlcNAc2-epimerase mRNA, PCR was performed using UDP-GlcNAc2-epimerase (EC 5.1.3.14) specific primers (15) (forward primer: 5'-GAGATG GTTCGAGTGATGC-3', reverse primer: 5'-TAACTATTTC ACCCTTCATGCT-3'). B-actin was also amplified using specific primers (forward primer: 5'-GACTATGACTTAGTT GCGTTA-3', reverse primer: 5'-GCCTTCATACATCTCAA GTTG-3') (15). All primers were synthesized by Bex Co., Ltd. (Tokyo, Japan). Amplification was performed with $5 \mu 1$ 10xExTaq Buffer (Takara), $4 \mu 1 \mathrm{dNTP}$ mix (Takara), $0.25 \mu 1$ rTaq (Takara), $38.25 \mu 1$ distilled water, forward and reverse primers ( $1 \mu 1$ each), and $1 \mu 1$ template cDNA using a GeneAmp PCR System 9700 (PE Applied Biosystems). Cycling conditions for amplification of UDP-GlcNAc 2epimerase mRNA were $30 \mathrm{sec}$ at $94^{\circ} \mathrm{C}, 60 \mathrm{sec}$ at $50^{\circ} \mathrm{C}$, and $90 \mathrm{sec}$ at $72^{\circ} \mathrm{C}$ for 70 cycles; and for $B$-actin, $30 \mathrm{sec}$ at $95^{\circ} \mathrm{C}$, $30 \mathrm{sec}$ at $55^{\circ} \mathrm{C}$, and $30 \mathrm{sec}$ at $72^{\circ} \mathrm{C}$ for 30 cycles. PCR-products were electrophoresed in a $2 \%$ agarose gel. The PCR products were visualized by staining with ethidium bromide. For analysis of growth inhibitory effects of siRNA transfection for UDP-GlcNAc2-epimerase, the number of lymphoma cells was counted by trypan-blue exclusion methods.

Quantitative real-time PCR analysis. Total RNA was extracted from HBL-8 cell lines using TRIsol (Invitrogen) according to the manufacturer's instructions. After adding $5 \mu \mathrm{g}$ of total RNA with $1 \mu \mathrm{l}$ of 1000 pmol random primers (Takara) and $1 \mu \mathrm{l}$ of $10 \mathrm{mM}$ dNTP mixture (Takara), reverse transcription was performed using SuperScript III Rnase H-Reverse Transcriptase (Invitrogen) according to the manufacturer's protocol. PCR was performed with the Quanti test SYBR Green PCR Master mix (Qiagen, USA) using UDP-GlcNAc2-epimerase (EC 5.1.3.14) specific primers (15) (forward primer: 5'-GAGATGGTTCGAGTGA TGC-3', reverse primer: 5'-TAACTATTTCACCCTTCAT GCT-3'). Cycling conditions for amplification of UDPGlcNAc 2-epimerase mRNA were $30 \mathrm{sec}$ at $94^{\circ} \mathrm{C}, 60 \mathrm{sec}$ at $50^{\circ} \mathrm{C}$, and $90 \mathrm{sec}$ at $72^{\circ} \mathrm{C}$ for 60 cycles. For human glyceraldehyde-3-phosphate dehydrogenase (GAPDH) mRNA, amplification was performed using forward primer (5'-ATCA CTGCCACCCAGAAG-3'), reverse primer (5'-CAGTGAGC TTCCCGTTCA-3'), and cycling conditions of $15 \mathrm{sec}$ at $94^{\circ} \mathrm{C}, 15 \mathrm{sec}$ at $60^{\circ} \mathrm{C}$, and $20 \mathrm{sec}$ at $72^{\circ} \mathrm{C}$ for 45 cycles. Real-time PCR reactions and data analysis were performed with LightCycler (Roche, Germany). The amount of mRNA was calculated based on the relative mRNA concentration (UDP-GlcNAc2-epimerase/GAPDH). 
Cell growth with metabolic complementation of sialic acid by ManNAc. In order to analyze the effects of resialylation by the sialic acid complementation assay, the HBL-8 3D2 clone cells were incubated with $30 \mathrm{mM}$ ManNAc or Man for $72 \mathrm{~h}$ at $37^{\circ} \mathrm{C}$, and then the number of lymphoma cells was counted by trypan-blue exclusion methods.

C6-ceramide or Sph-induced cell death. HBL-8 clones were grown for 2 days and then seeded at $37^{\circ} \mathrm{C}$ in 96-well microtiter plates at $5 \times 10^{4}$ cells/well in $100 \mu 1$ phenol red and serum-free culture medium containing C6-ceramide (final concentrations: $20 \mu \mathrm{M}$ ) (Sigma) or Sph (Biomol Research Laboratories, Inc., USA) at various concentrations for various lengths of time. Next, $10 \mu 1$ of WST-1 reagent was added to each well, and the plates were incubated for $1 \mathrm{~h}$ or $2 \mathrm{~h}$ at $37^{\circ} \mathrm{C}$. The plates were then shaken for $1 \mathrm{~min}$ at room temperature, and the absorbance at $450-655 \mathrm{~nm}$ or $450 \mathrm{~nm}$ was measured using a model 550-microplate reader (Bio-Rad, CA, USA). To evaluate the effects of cell surface desialylation, $5 \times 10^{6}$ cells were incubated at $37^{\circ} \mathrm{C}$ for $30 \mathrm{~min}$ in $200 \mu \mathrm{l}$ of RPMI-1640 containing $15 \%$ fetal calf serum and $40 \mu \mathrm{l}$ of $1 \mathrm{U} / \mathrm{ml}$ Vibrio cholerae neuraminidase (Boehringer-Mannheim) before incubation with C6-ceramide or Sph. For analysis of the effects of resialylation by the sialic acid complementation assay, the HBL-8 3D2 clone cells were incubated with $30 \mathrm{mM}$ ManNAc or Man for $72 \mathrm{~h}$ at $37^{\circ} \mathrm{C}$, and then the cell death induced by C6-ceramide was evaluated by WST-1 assay as previously described.

To evaluate the effects of cell surface desialylation by knockdown of UDP-GlcNAc2-epimerase using siRNA, siRNA was transfected into the HBL-8 $3 \mathrm{G} 3$ clone cells as described above. After 72-h incubation with siRNA, the HBL-8 3G3 clone cells were incubated with C6-ceramide (final concentration: $40 \mu \mathrm{M}$ ) for $12 \mathrm{~h}$ and then cell viability was analyzed by WST-1 methods as described above.

Membrane permeability detected by $\mathrm{LDH}$ release assay. HBL-8 clones were grown for 2 days and then seeded at $37^{\circ} \mathrm{C}$ in 96 -well microtiter plates at $5 \times 10^{4}$ cells/well in $50 \mu 1$ phenol-red and serum-free culture medium containing C6ceramide (final concentration: $40 \mu \mathrm{M}$ ) (Sigma) for $1 \mathrm{~h}$ at RT. Then the amount of LDH release was quantified using the Cytotoxicity detection kit (Roche, Germany) with slight modifications. First, $100 \mu 1$ of reaction mixture solution (included in the kit, according to the manufacturer's instruction) reagent was added to each well, and the plates were incubated for $5 \mathrm{~min}$ at RT. Stop solution $(50 \mu \mathrm{l})$ was added to each well and the absorbance at 450-655 nm was measured using a model 550-microplate reader (Bio-Rad). The experiment was performed on $3 \mathrm{G} 3$ and $3 \mathrm{D} 2$ clones to compare the amount of LDH between them. To evaluate the effects of cell surface desialylation, $5 \times 10^{6}$ cells were incubated at $37^{\circ} \mathrm{C}$ for $60 \mathrm{~min}$ in $200 \mu \mathrm{l}$ of RPMI-1640 containing $15 \%$ fetal calf serum and $40 \mu \mathrm{l}$ of $1 \mathrm{U} / \mathrm{ml}$ Vibrio cholerae neuraminidase (Boehringer-Mannheim) before incubation with C6-ceramide.

Caspase in C6-ceramide-induced cell death. Two HBL-8 clones were grown for 2 days and then seeded at $37^{\circ} \mathrm{C}$ in 96-well microtiter plates at $5 \times 10^{4}$ cells/well in $100 \mu 1$ phenol- red and serum-free culture medium with or without broad caspase inhibitor, z-VAD-fmk $(120 \mu \mathrm{M})$ (Peptide Institute, Japan) at $37^{\circ} \mathrm{C}$ for $30 \mathrm{~min}$. Then cells were incubated with C6-ceramide (final concentration: $20 \mu \mathrm{M}$ ) (Sigma) at $37^{\circ} \mathrm{C}$ for $24 \mathrm{~h}$ with or without $\mathrm{z}-\mathrm{VAD}-\mathrm{fmk}(120 \mu \mathrm{M})$. Then cell viability was evaluated by WST-1 assay as described above.

Involvement of PI3K in C6-ceramide-induced cell death. Two HBL-8 clones were grown for two days and then seeded at $37^{\circ} \mathrm{C}$ in 96 -well microtiter plates at $5 \times 10^{4}$ cells/well in $100 \mu 1$ phenol-red and serum-free culture medium with or without PI3K inhibitor, LY294002 $(60 \mu \mathrm{M})\left(\right.$ Calbiochem) at $37^{\circ} \mathrm{C}$ for $30 \mathrm{~min}$. Then cells were incubated with C6-ceramide (final concentration: $40 \mu \mathrm{M})\left(\right.$ Sigma) at $37^{\circ} \mathrm{C}$ for $3 \mathrm{~h}$ with or without LY294002 $(60 \mu \mathrm{M})$. Then cell viability was evaluated by WST-1 assay as described above.

Morphology of cell death. Giemsa-stained Cytospin ${ }^{\circledR}$ HBL-8 cell preparations were evaluated for morphological changes during ceramide-induced cell death.

\section{Results}

Cell surface sialylation on HBL-8 clones. Flow cytometric analysis showed that the $3 \mathrm{G} 3$ clone of HBL- 8 cells showed substantial cell surface binding of LFA lectin, but only slight binding was found on the 3D2 clone (Fig. 1a). In the sialic acid metabolic complementation assay, cell surface resialylation was observed in the 3D2 clone by complementation of ManNAc into the culture medium, but not by complementation of GlcNAc and Man (Fig. 1b). Transfection of siRNA for UDP-GlcNAc2-epimerase in the HBL-8 3G3 clone showed a reduction in MAA lectin reactivity (negative cont siRNA: $82.89 \%$ - siRNA for epimerase: $67.38 \%=\sim 15 \%$ reduction) compared to that for the negative control siRNA (Fig. 1c). RT-PCR analysis showed that transfection of siRNA inhibited expression of UDP-GlcNAc2-epimerase mRNA compared to that of the negative control, and that there was no significant difference in the expression of $\beta$-actin between the two clones (Fig. 1d). Real-time RT-PCR analysis also revealed that the relative concentration (UDP-GlcNAc2epimerase/GAPDH) decreased for the UDP-GlcNAc2epimerase siRNA knock-down compared to that of the negative control siRNA transfection (Fig. 1e). For the siRNA knockdown, the number of lymphoma cells decreased compared to the negative control experiment after 72-h incubation (Fig. 1f). The number of 3D2 clone cells markedly increased upon incubation with ManNAc, which is effective for cell surface resialylation, but not with mannose (Man), which is not effective for cell surface resialylation (Fig. 1g).

C6-ceramide- or Sph-induced cell death. The highly sialylated 3G3 clone was less sensitive to C6-ceramide. On the other hand, cell death of the hyposialylated 3D2 clone was markedly induced by treatment with C6-ceramide (Fig. 2a). The neuraminidase treatment enhanced the amount of cell death induced by C6-ceramide in the highly sialylated 3G3 clone (Fig. 2b). Clone $3 \mathrm{G} 3$ was less sensitive to Sph than the 3D2 clone (Fig. 2c). Pretreatment with neuraminidase enhanced Sph-induced cell death in the $3 \mathrm{G} 3$ clone (Fig. 2d). 
a

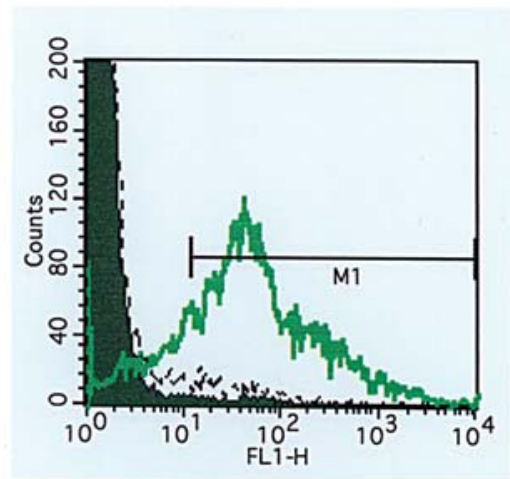

b

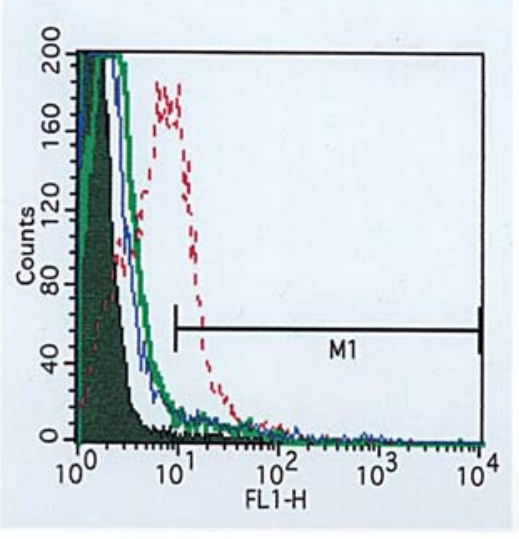

d

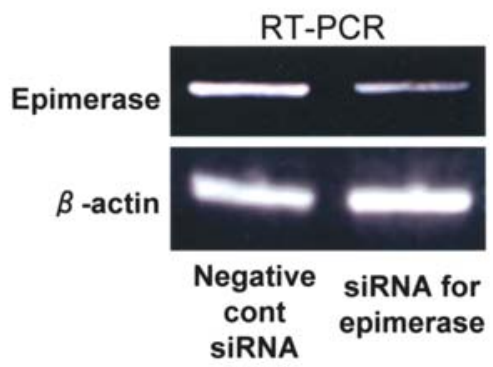

3D2

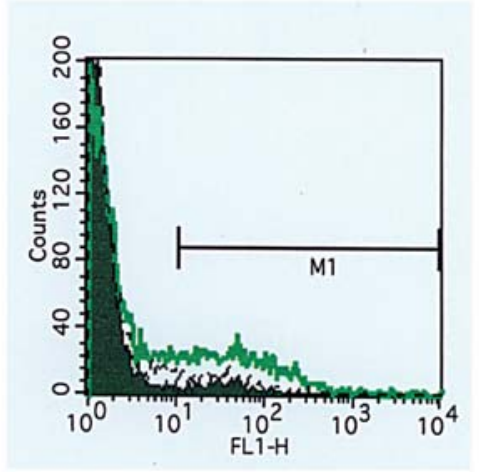

c

MAA

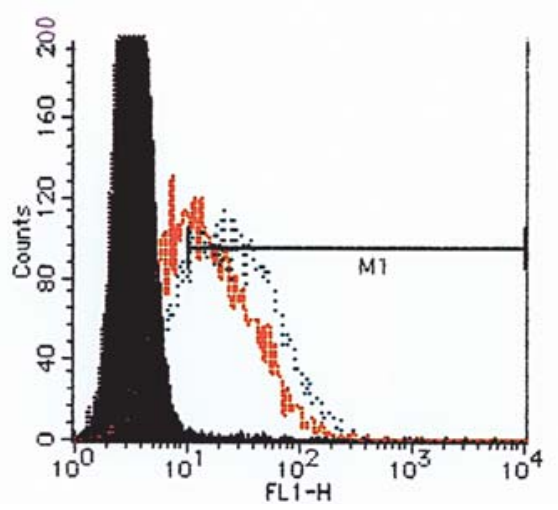

e

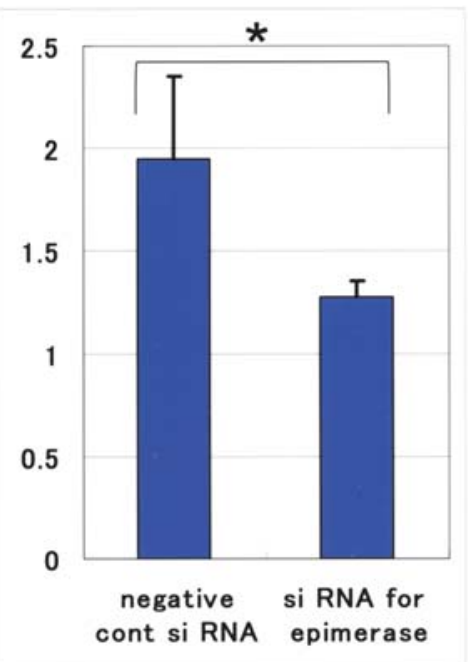

Relative conc.

(Epimerase / GAPDH) of m RNA

Figure 1. (a) Analysis of cell surface sialylation by flow cytometry. Cell surface sialylation in the 3G3 and 3D2 clones of HBL-8 cells. Solid and dotted lines show LFA binding without or with neuraminidase treatment, respectively. Dark areas indicate the negative controls. Substantial LFA lectin binding was found in the 3G3 clone, but only weak binding was found in the 3D2 clone. The data shown are representative of two independent experiments. (b) Analysis of LFA lectin reactivity. In the sialic acid metabolic complementation assay, cell surface resialylation was observed by complementation of $10 \mathrm{mM}$ ManNAc for $72 \mathrm{~h}$ at $37^{\circ} \mathrm{C}$ in culture medium, but not for GlcNAc and Man in the 3D2 clone. The solid line shows GlcNAc and Man, and the dotted line shows ManNAc. The data shown are representative of two independent experiments. (c) Transfection of siRNA for UDP-GlcNAc2-epimerase in the HBL-8 3G3 clone shows the reduction of MAA lectin reactivity compared to negative control siRNA. The thin dotted line represents MAA lectin reactivity with negative control siRNA, and the thick dotted line represents reactivity with siRNA for UDP-GlcNAc2-epimerase. Approximately a 15\% reduction in MAA lectin reactivity [negative cont siRNA (dotted line): $82.89 \%$ - siRNA for epimerase (thick line): $67.38 \%=\sim 15 \%$ reduction] was found after transfection with siRNA. The data shown are representative of two independent experiments. (d) RT-PCR analysis reveals that mRNA expression of UDP-GlcNAc2-epimerase was inhibited by siRNA knockdown of UDP-GlcNAc2-epimerase compared to the negative control siRNA, and that there is no significant difference in the expression of $\beta$-actin between the two clones. The data shown are representative of two independent experiments. (e) Real-time RT-PCR analysis reveals that the relative concentration (UDP-GlcNAc2-epimerase/GAPDH) was decreased by siRNA knockdown of UDP-GlcNAc2-epimerase compared to the negative control siRNA transfection ( $\left.{ }^{*} \mathrm{p}=0.0473\right)$. The vertical line represents the relative concentration (epimerase/GAPDH) of mRNA. The data shown are representative of two independent experiments. 
f

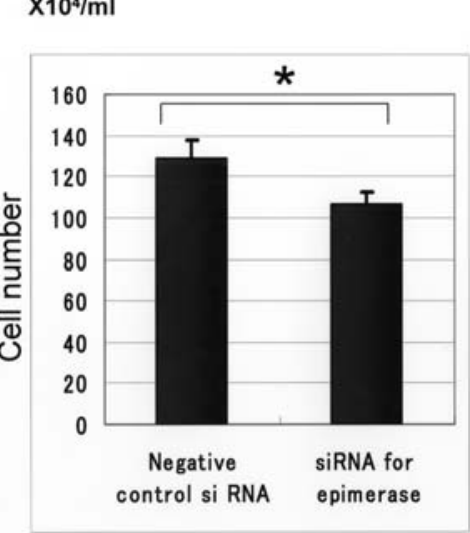

g $\quad \times 10^{4} / \mathrm{ml}$

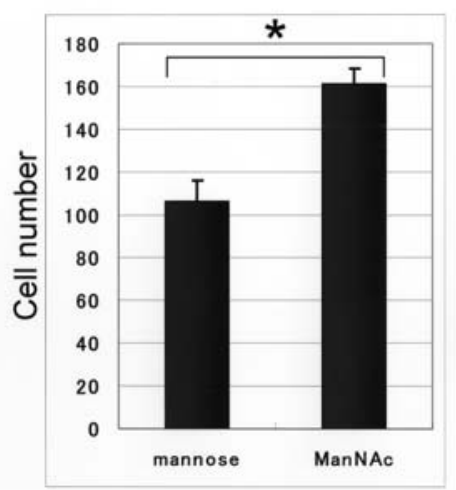

Figure 1 (continued). (f) Effects of siRNA for UDP-GlcNAc2-epimerase on the proliferation of lymphoma cells. For siRNA knockdown of UDP-GlcNAc2epimerase, the number of lymphoma cells was decreased compared to the negative control siRNA transfection after 72-h incubation (" $\mathrm{p}=0.0230$ ). The vertical line represents the number of proliferating cells. The data shown are representative of two independent experiments performed in triplicate. (g) The number of lymphoma cells in the 3D2 clone was markedly increased with incubation with ManNAc, but not with mannose ( $\mathrm{p}=0.0219)$. The vertical line represents the number of proliferating cells. The data shown are representative of two independent experiments.

$\mathbf{a}$

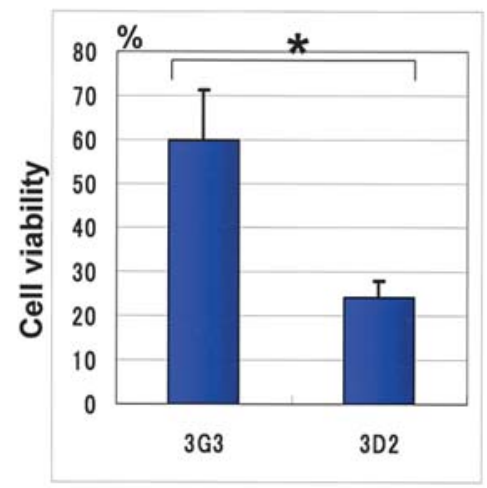

c

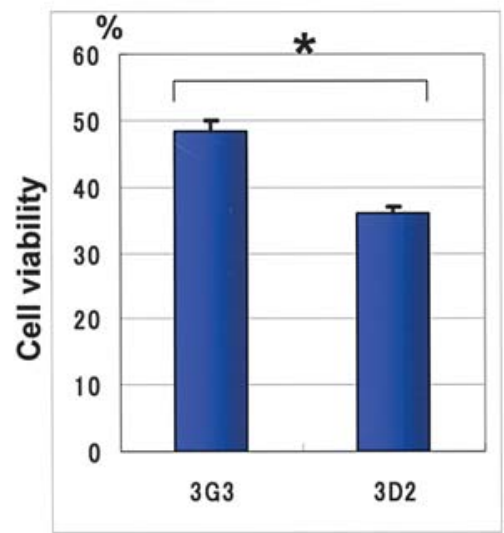

b

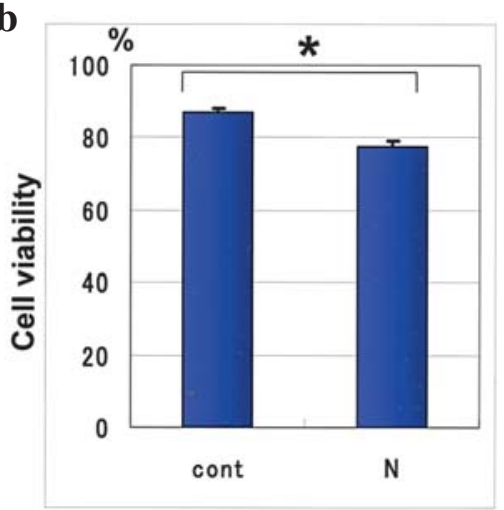

d

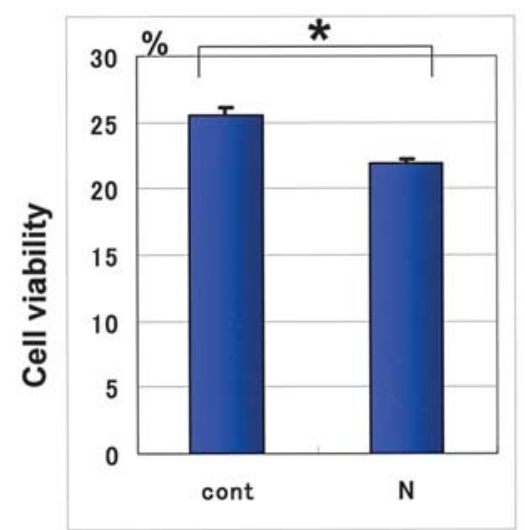

Figure 2. C6-ceramide or Sph-induced cell death on HBL-8 clones. (a) Effect of C6-ceramide on the viability of HBL-8 clones was assessed by a WST-1 assay. The highly sialylated 3G3 clone was less sensitive to C6-ceramide. On the other hand, in the hyposialylated 3D2 clone, treatment with C6-ceramide markedly induced cell death. C6-ceramide: $20 \mu \mathrm{M}, 24 \mathrm{~h}\left({ }^{*} \mathrm{p}=0.0059\right)$. The vertical line represents the percentage of cell viability after C6-ceramide treatment compared to that of methanol alone according to the WST-1 assay. The data show representative of two independent experiments performed in triplicate. (b) Effect of C6-ceramide on the viability of the HBL-8 3G3 clone was assessed by a WST-1 assay. The neuraminidase treatment enhanced the amount of cell death induced by C6-ceramide in the highly sialylated $3 \mathrm{G} 3$ clone. C6-ceramide: $30 \mu \mathrm{M}, 4 \mathrm{~h}\left({ }^{*} \mathrm{p}=0.0006\right)$; , neuraminidase treatment. The vertical line represents the percentage of cell viability after C6-ceramide treatment compared to that of methanol alone according to the WST-1 assay. The data shown are representative of two independent experiments performed in triplicate. (c) Effect of Sph on the viability of HBL-8 clones was assessed by a WST-1 assay. Clone $3 \mathrm{G} 3$ was less sensitive to Sph than the 3D2 clone ( $\left.{ }^{*} \mathrm{p}=0.0003\right)$. The vertical line represents the percentage of cell viability after Sph treatment compared to that of ethanol alone according to the WST-1 assay. The data shown are representative of two independent experiments performed in triplicate. (d) Effect of Sph on the viability of the HBL-8 3G3 clone was assessed by a WST-1 assay. Pretreatment with neuraminidase enhanced Sph-induced cell death in the 3G3 clone $\left({ }^{*} \mathrm{p}=0.0008, \mathrm{~N}\right.$, neuraminidase treatment). The vertical line represents the percentage of cell viability after Sph treatment compared to that of ethanol alone according to the WST-1 assay. The data shown are representative of two independent experiments performed in triplicate. 

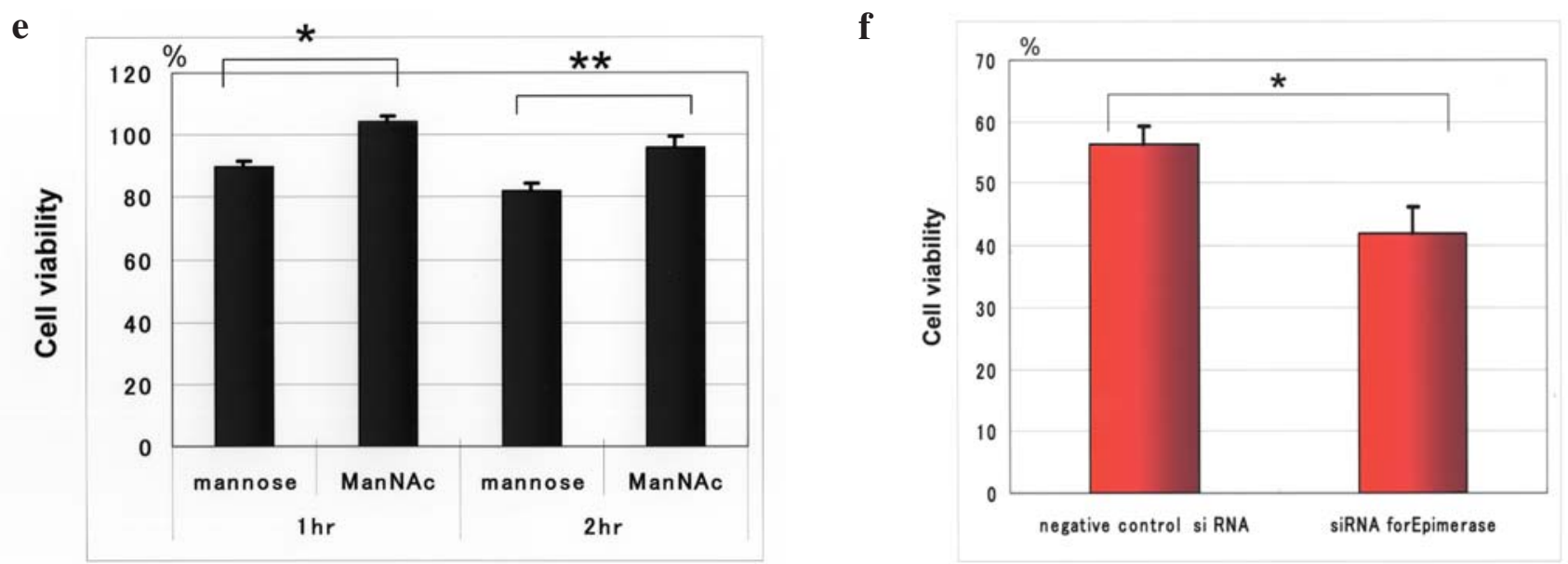

Figure 2 (continued). (e) Sialic acid complementation assay showed that supplementation with ManNAc (30 mM, 72 h) inhibited C6-ceramide-induced cell death in the 3D2 clone ( $1 \mathrm{~h}, 2 \mathrm{~h}, 1$ - or 2 -h incubation with C6-ceramide) $\left({ }^{*} \mathrm{p}=0.0004,{ }^{* *} \mathrm{p}=0.0070\right)$ compared to supplementation with mannose. The vertical line represents the percentage of cell viability after C6-ceramide treatment compared to that of methanol alone according to the WST-1 assay. The data shown are representative of two independent experiments. (f) Cell viability of the HBL-8 $3 \mathrm{G} 3$ clone was decreased by incubation with C6-ceramide (40 $\mu \mathrm{M}$ for $12 \mathrm{~h}$ ) for the UDP-GlcNAc2-epimerase siRNA knockdown compared to the negative control after 72-h incubation ( $\mathrm{p}=0.0076)$. The vertical line represents the percentage of cell viability after C6-ceramide treatment compared to that of methanol alone according to the WST-1 assay. The data shown are representative of two independent experiments performed in triplicate. In each experiment statistical significance was determined by the Student's t-test. Values represent mean cell viability $\pm \mathrm{SD}$.

$\mathbf{a}$

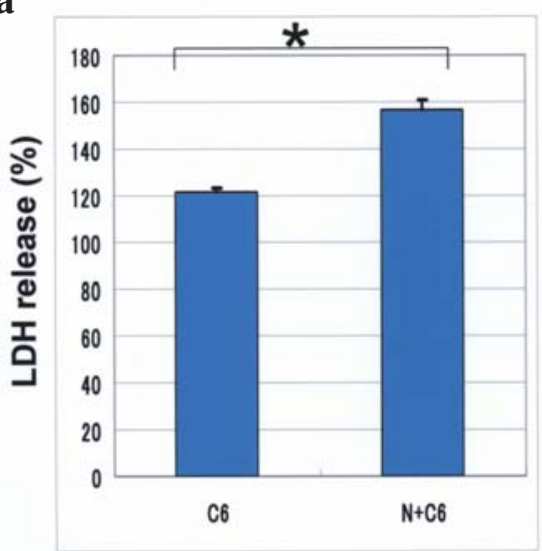

b

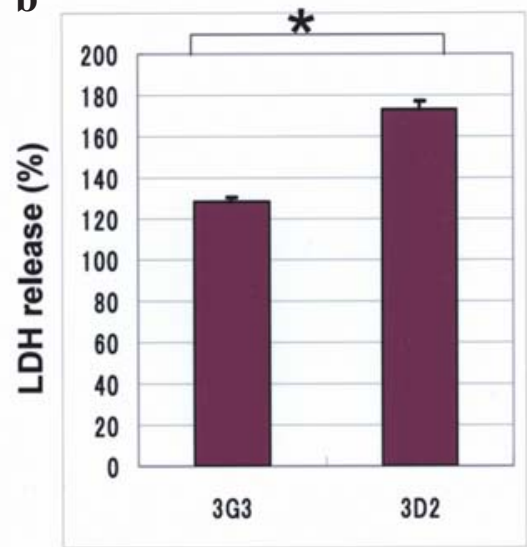

Figure 3. The amount of extracellularly released LDH was detected using the Cytotoxicity detection kit. The percentage of extracellularly released LDH was calculated as (C6-ceramide treatment condition/non-treatment condition) x 100. (a) The amount of released LDH was enhanced with neuraminidase pre-treatment in the HBL-8 3G3 highly sialylated clone treated with C6-ceramide (40 $\mu \mathrm{M}, 60 \mathrm{~min}$.) ( $\mathrm{p}=0.0002$, C6, C6-ceramide; N, neuraminidase treatment). The data shown are representative of two independent experiments performed in triplicate. (b) The amount of released LDH was greater for the 3D2 clone as compared to the $3 \mathrm{G} 3$ clone with $\mathrm{C} 6$-ceramide treatment $(40 \mu \mathrm{M}, 120 \mathrm{~min})\left({ }^{*} \mathrm{p}<0.0001\right.$; C6, C6-ceramide). The data shown are representative of two independent experiments performed in triplicate. In each experiment statistical significance was determined by the Student's t-test. Values represent mean cell viability $\pm \mathrm{SD}$.

Clone 3G3 was less sensitive to S-1-P than the 3D2 clone (data not shown). The sialic acid metabolic complementation assays using several precursors of sialic acid in the 3D2 clone showed that supplementation with ManNAc $(30 \mathrm{mM}$, $72 \mathrm{~h}$ ) inhibited C6-ceramide-induced cell death compared to that with Man (Fig. 2e). The cell viability of the 3G3 clone with siRNA knockdown of UDP-GlcNAc2-epimerase decreased with incubation with C6-ceramide ( $40 \mu \mathrm{M}$ for $12 \mathrm{~h}$ ) more so than that of the negative control siRNA transfection after 72-h incubation (Fig. 2f).

Membrane permeability detected by $L D H$ release assay. The amount of extracellularly released LDH was detected with the Cytotoxicity detection kit. The amount of released LDH was enhanced with neuraminidase pre-treatment in the highly sialylated 3G3 clone treated with C6-ceramide ( $40 \mu \mathrm{M}, 60 \mathrm{~min})$ (Fig. 3a). The amount of released LDH was more for the $3 \mathrm{D} 2$ clone compared to the $3 \mathrm{G} 3$ clone when treated with C6-ceramide (40 $\mu \mathrm{M}, 120 \mathrm{~min}$ ) (Fig. 3b).

Analysis of C6-ceramide induced cell death by Annexin-V and PI staining. The HBL-8 3G3 clone was less sensitive to C6-ceramide $(40 \mu \mathrm{M}, 24 \mathrm{~h})$ and 3D2 was relatively more sensitive to C6-ceramide than that of the $3 \mathrm{G} 3$ clone. Almost all of the dead cells from C6-ceramide-induced cell death were PI-positive, necrotic cells, but not apoptotic cells (Fig. 4). 
3G3

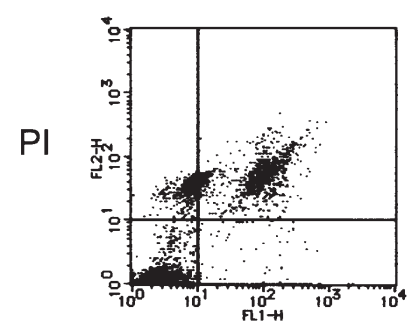

Annexin V

3D2

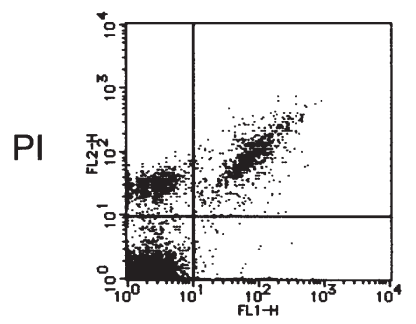

Annexin V
3G3+C6-ceramide

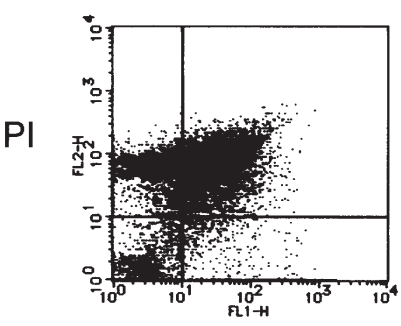

Annexin V

$\mathrm{Pl}$

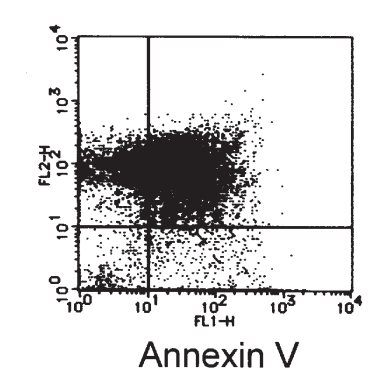

Figure 4. Analysis of C6-ceramide-induced cell death by Annexin-V and PI staining. In the HBL-8 clones, C6-ceramide (40 $\mu \mathrm{M}, 24 \mathrm{~h})$ induced cell death in both clones. The 3G3 clone was less sensitive to C6-ceramide (necrosis with treatment, 80.84\%; control, 12.73\%; C6-ceramide contribution, 68.11\%) and 3D2 was more sensitive to C6-ceramide (necrosis with treatment, 88.04\%; control, 14.88\%; C6-ceramide contribution, $73.16 \%$ ) than that of the 3G3 clone. Almost all of the C6-ceramide-induced cell death was necrotic (PI-positive cells) rather than apoptotic. The data shown are representative of two independent experiments.

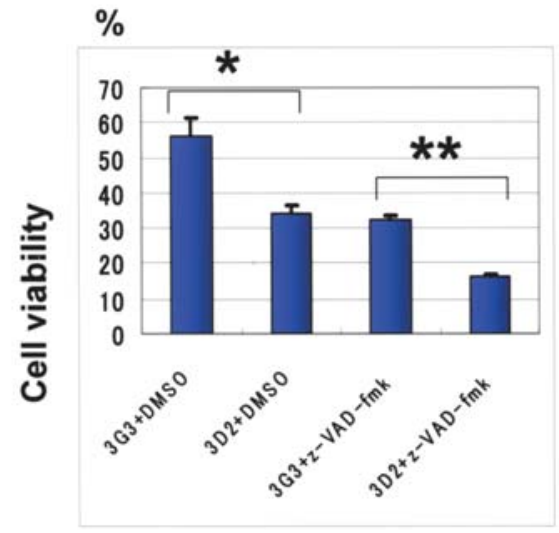

Figure 5. Involvement of caspase in C6-ceramide-induced cell death. C6ceramide induced cell death in both the $3 \mathrm{G} 3$ and $3 \mathrm{D} 2$ clones, and clone $3 \mathrm{G} 3$ was less sensitive to C6-ceramide than the 3D2 clone $\left({ }^{*} \mathrm{p}=0.0022\right.$, $\left.{ }^{* *} \mathrm{p}<0.0001\right)$. Furthermore, C6-ceramide-induced cell death was not blocked by z-VAD-fmk, and the amount of cell death was significantly enhanced by pretreatment with z-VAD-fmk in both clones. Cell viability was evaluated by WST-1 assay. The vertical line represents the percentage of cell viability after C6-ceramide treatment compared to that of methanol alone according to the WST-1 assay. Statistical significance was determined by the Student's t-test. Values represent mean cell viability \pm SD. The data shown are representative of two independent experiments performed in triplicate.

Involvement of caspase in C6-ceramide-induced cell death. C6-ceramide induced cell death in both the 3G3 and 3D2 clones, and the $3 \mathrm{G} 3$ clone was less sensitive to C6-ceramide than the 3D2 clone (Fig. 5). Furthermore, C6-ceramide-induced cell death was not blocked by z-VAD-fmk, and the amount

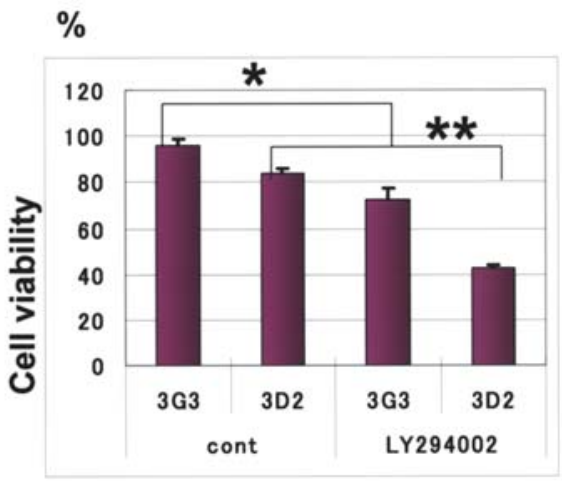

Figure 6. PI3K and C6-ceramide-induced cell death. The amount of C6ceramide- $(40 \mu \mathrm{M}, 3 \mathrm{~h})$ induced cell death was enhanced after pretreatment with PI3K inhibitor, LY294002 $\left(60 \mu \mathrm{M}\right.$, at $37^{\circ} \mathrm{C}$ for $\left.30 \mathrm{~min}\right)\left({ }^{*} \mathrm{p}=0.0023\right.$, $\left.{ }^{* *} \mathrm{p}<0.0001\right)$ in both HBL-8 clones. The vertical line represents the percentage of cell viability after C6-ceramide treatment compared to that of methanol alone according to the WST-1 assay. In each experiment statistical significance was determined by the Student's t-test. Values represent mean cell viability \pm SD. The data of each experiment shown are representative of two independent experiments performed in triplicate.

of cell death was enhanced by pretreatment with z-VAD-fmk in both clones.

Involvement of PI3K on C6-ceramide-induced cell death. The amount of C6-ceramide-induced cell death was enhanced after pretreatment with PI3K inhibitor, LY294002 in both HBL-8 clones (Fig. 6). 

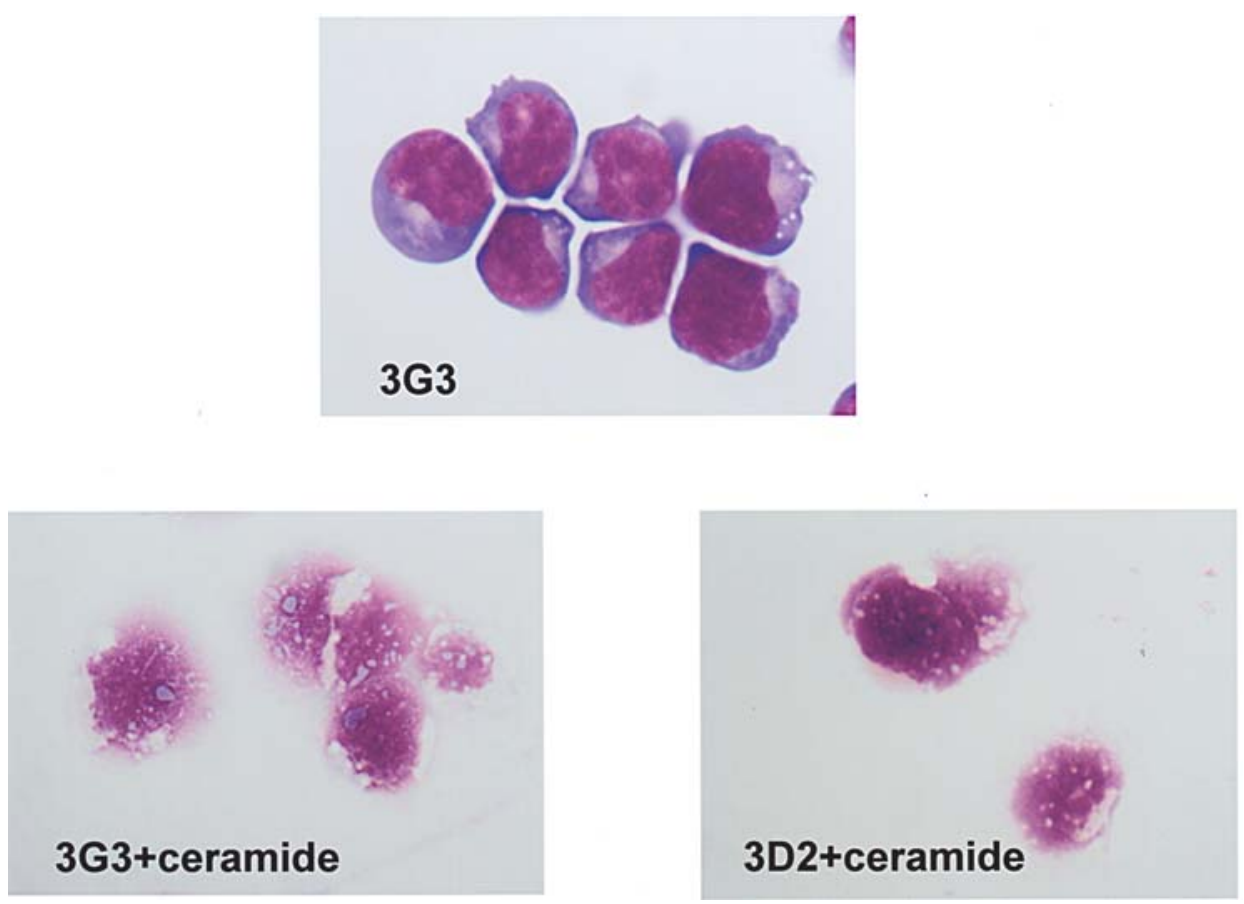

Figure 7. Morphological changes upon ceramide-induced cell death. In both the 3G3 and 3D2 clones, lymphoma cells incubated with C6-ceramide (40 $\mu \mathrm{M}$, $24 \mathrm{~h}$ ) showed cell swelling and cytoplasmic vacuoles. These features are characteristic of necrotic cell death. The data is representative of two independent experiments.

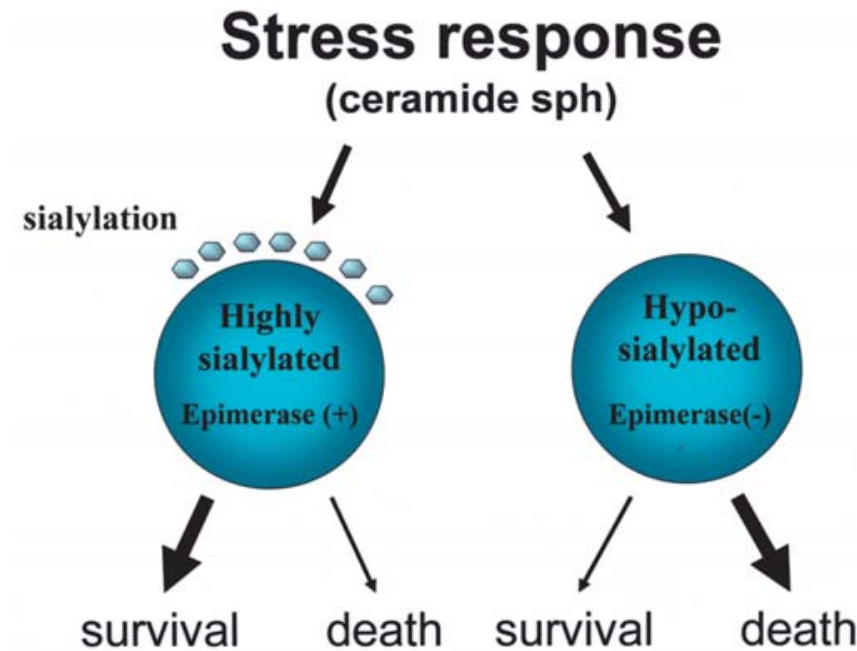

Figure 8. Schematic representation of the relationship between cell surface sialylation and ceramide or sph-induced cell death. Under stressful conditions, a highly sialylated cell surface protects lymphoma cells from ceramide or sph-induced cell death, whereas hyposialylation enhances the sensitivity to ceramide or sph-induced cell death.

Morphological changes during ceramide-induced cell death. Both 3G3 and 3D2 clones incubated with C6-ceramide ( $40 \mu \mathrm{M}$, $24 \mathrm{~h}$ ) showed cell swelling and the appearance of cytoplasmic vacuoles (Fig. 7), and the morphological appearance indicated necrosis, not apoptosis.

\section{Discussion}

Stress signals are considered to produce ceramide through the sphingomyelin pathway, for example via sphingomyelinase

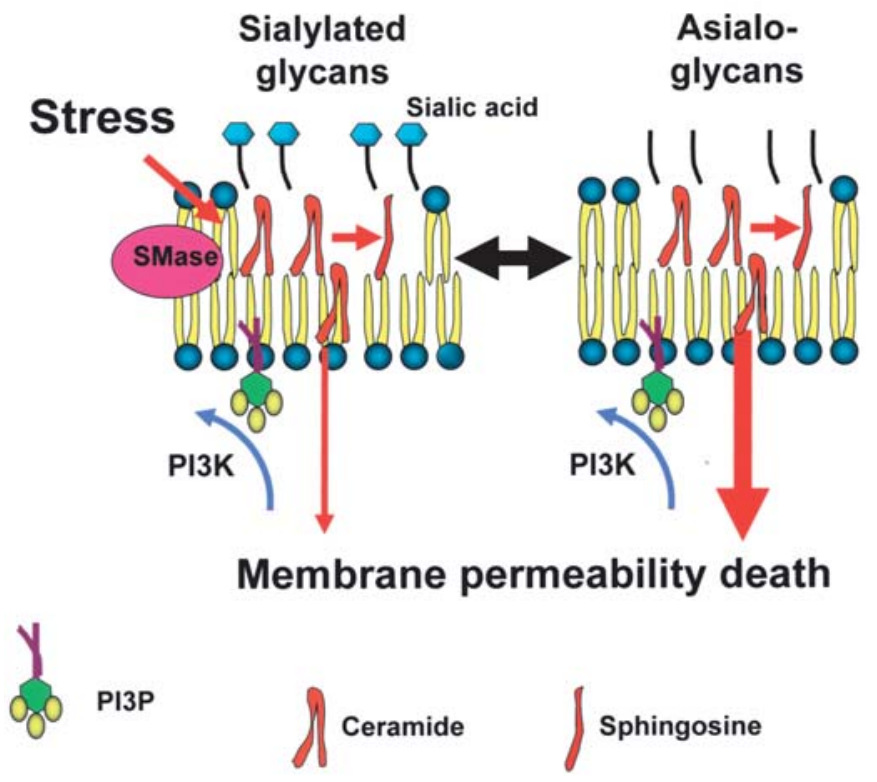

Figure 9. A schematic representation of the regulatory mechanism of cell surface sialylation in ceramide or sph-induced membrane permeability death, including the kinase-dependent regulatory mechanisms in ceramide or sph-induced cell death.

(SMase) activity and following cell death $(18,19)$. Ceramide is converted to sphingosine by the activity of ceramidase and is subsequently converted to sphingosine-1-phosphate by the activity of sphingosine kinase (20) at the cell surface or extracellular milieu (21). Sphingosine induces rapid, necrotic cell death (22). In the present study, cell surface sialylation appears to be closely associated with ceramide or sphingosineinduced cell death. As shown in Fig. 8, cell surface sialylation 
regulates the susceptibility to ceramide and sphingolipids, and in a condition such as a marked stress response, which produces ceramide or sphingolipids, cell surface sialylation protects lymphoma cells from ceramide or sphingolipidinduced cell death.

The present study showed cell death induced by C6ceramide was regulated by cell surface sialylation and was independent of caspase activation. Ceramide-induced apoptosis has been reported to be mitochondria-mediated and caspasedependent (26), in other studies, C2-ceramide has been reported to enhance caspase-dependent cell death in a glioma cell line (27), or to induce caspase-independent necrosis showing cytoplasmic vacuolation (28). In addition, necrotic cell death is found to be enhanced by treatment with z-VADfmk (29). Therefore, cell death induced by C6-ceramide in HBL- 8 clones seems to be enhanced by treatment with z-VADfmk, suggesting that blocking caspase activation enhances the amount of cell death through the necrotic pathway. Flow cytometric analysis showed that almost all of the dead cells induced by C6-ceramide were positive for PI, suggesting the enhancement of cell membrane permeability by C6-ceramide, and the LDH release assay revealed that cell surface sialylation inhibits C6-ceramide-mediated membrane permeability of $3 \mathrm{G} 3$ clone cells. Therefore, there is a possibility that the difference in C6-ceramide mediated membrane permeability between the HBL- 8 clones is regulated by cell surface sialylation. Furthermore, cell death induced by ceramide showed cell swelling and cytoplasmic vacuoles. These morphological features are consistent with necrosis rather than apoptosis $(28,29)$. Taken together, these data indicate that cell death induced by ceramide in HBL- 8 clones appears to be caspase-independent necrosis and that the differences in the amount of necrosis are regulated by cell surface sialylation. Goni and Alonso, recently reported that ceramide and sphingolipids modified the physical properties of the cell membrane (16), and Montes et al reported that ceramide induced an increased efflux or permeability in cell membranes (30). Therefore, the evidence suggests that ceramide or sphingolipids induce the enhancement of membrane permeability death through a caspase-independent pathway, and consequently necrotic cell death and cell membrane permeability induced by ceramide are regulated by cell surface sialylation.

There have been several reports on the correlation between PI3K and the sphingomyelinase pathway as a mechanism for cell survival/death decisions involving cross-talk between the pathways (31). PI3K activity is reported to be inhibited by ceramide (32). In the present study, as shown in Fig. 9, the PI3K inhibitor, LY294002 enhanced the amount of C6ceramide-induced cell death in both HBL-8 clones. Therefore, the activity of PI3K appears to inhibit C6-ceramide-induced cell death.

There was a significant difference in the susceptibility of the HBL- 8 clones to ceramide or Sph, and an increase of cell surface sialylation reduced susceptibility of the clone cells to ceramide or Sph-induced cell death. Neuraminidase treatment enhanced cell death induced by C6-ceramide in the highly sialylated 3G3 clone. Furthermore, the sialic acid complementation assay using ManNAc in the hyposialylated 3D2 clone showed that cell surface resialylation by ManNAc complementation inhibited cell death induced by ceramide. These data suggest that cell surface sialic acid can protect lymphoma cells from ceramide-induced cell death. A highly sialylated 3G3 clone has been found to be more metastatic than a hyposialylated 3D2 clone in the metastatic SCID mouse model of human lymphoma cell lines (5). Lymphoma cells may be exposed to a stressful environment in the blood stream or in distant target organs upon metastasis, and various stresses induce ceramide or sphingolipid which is produced by the sphingomyelin pathway in vivo (19). In addition, the inhibition of cell death is reported to be a crucial characteristic of metastatic cancer cells (33). Therefore increased cell surface sialylation may reduce susceptibility of the $3 \mathrm{G} 3$ clone cells to ceramide or sphingolipid-induced cell death, leading to increased metastatic colonization of distant target organs. mRNA expression of UDP-GlcNAc2-epimerase is known to correlate with the sialic acid content among two clones of HBL-8, 3G3 and 3D2 (15), and in our experiments, the knockdown of UDP-GlcNAc2-epimerase for the highly sialylated 3G3 clone decreased cell surface sialylation and also enhanced C6-ceramide-induced cell death. These data suggest that cell surface sialylation by expression of UDPGlcNAc2-epimerase is closely associated with the inhibition of ceramide-induced cell death, and that lymphoma cells may escape from stress-induced cell death through cell surface sialylation regulated by UDP-GlcNc2-epimerase, leading to an increase of metastatic colonization of distant organs.

In conclusion, cell death induced by ceramide and its metabolites in a human Burkitt's lymphoma cell line appears to be influenced by cell surface sialylation. This mechanistic model may provide a new scientific foundation in tumor cell biology of human malignant lymphoma.

\section{Acknowledgments}

We would like to thank Ms. M. Satoh for technical assistance and advice.

\section{References}

1. Kelm S and Schauer R: Sialic acids in molecular and cellular interactions. Int Rev Cytol 175: 137-240, 1997.

2. Schirrmacher V, Altefogt P, Fogel M, Dennis JW, Waller CA, Barz D, Schwartz V, Cheingsong-Popov R, Springer G, Robinson PJ, Nebe T, Brossmer W, Vlodavsky I, Paweletz N, Zimmermann H-P and Uhlenbruck G: Importance of cell surface carbohydrates in cancer cell adhesion, invasion and metastasis. Invasion Metastasis 2: 313-360, 1982.

3. Altevogt P, Fogel M, Cheingsong-Popov R, Dennis J, Robinson P and Schirrmacher V: Different patterns of lectin binding and cell surface sialylation detected on related high- and low-metastatic tumor lines. Cancer Res 43: 5138-5144, 1983.

4. Yogeeswaran G and Salk PL: Metastatic potential is positively correlated with cell surface sialylation of cultured murine tumor cell lines. Science 212: 1514-1516, 1981.

5. Abe M, Suzuki O, Tasaki K, Tominaga K and Wakasa $\mathrm{H}$ : Analysis of lectin binding properties on human Burkitt's lymphoma cell lines that show high spontaneous metastasis to distant organs in SCID mice: the binding sites for soybean agglutinin lectin masked by sialylation are closely associated with metastatic lymphoma cells. Pathol Int 46: 977-983, 1996.

6. Dennis JW, Waller C, Timpl R and Schirrmacher V: Surface sialic acid reduces attachment of metastatic tumor cells to collagen type IV and fibronectin. Nature 300: 274-276, 1982.

7. Fogel M, Altefogt P and Schirrmacher V: Metastatic potential severely altered by changes in tumor cell adhesiveness and cellsurface sialylation. J Exp Med 157: 371-376, 1983. 
8. Suzuki O, Nozawa Y, Kawaguchi T and Abe M: Phaseolus vulgaris leukoagglutinating lectin-binding reactivity in human diffuse large B cell lymphoma and its relevance to the patient's clinical outcome: lectin histochemistry and lectin blot analysis. Pathol Int 49: 874-880, 1999.

9. Suzuki O, Nozawa Y, Kawaguchi T and Abe M: Alpha-2,6sialylation of L-PHA reactive oligosaccharides and expression of $\mathrm{N}$-acetyl glucosaminyltransferase $\mathrm{V}$ in human diffuse large $\mathrm{B}$ cell lymphoma. Oncol Rep 10: 1759-1764, 2003.

10. Keppler OT, Peter ME, Hinderlich S, Moldenhauer G, Stehling P, Schmitz I, Schwartz-Albiez R, Reutter W and Pawlita M: Differential sialylation of cell surface glycoconjugates in a human B lymphoma cell line regulates susceptibility for CD95(APO1/Fas)-mediated apoptosis and for infection by a lymphotropic virus. Glycobiology 9: 557-569, 1999.

11. Peter ME, Hellbardt S, Schwartz-Albiez R, Westendorp MO, Walczak H, Moldenhauer G, Grell M and Krammer PH: Cell surface sialylation plays a role in modulating sensitivity towards APO-1-mediated apoptotic cell death. Death Differ 2: 163-171, 1995.

12. Suzuki O, Nozawa Y and Abe M: Sialic acids linked to glycoconjugates of Fas regulate the caspase-9-dependent and mitochondria-mediated pathway of Fas-induced apoptosis in Jurkat T cell lymphoma. Int J Oncol 23: 769-774, 2003.

13. Keppler OT, Hinderlich S, Langner J, Schwartz-Albiez R, Reutter W and Pawlita M: UDP-GlcNAc2-epimerase: a regulator of cell surface sialylation. Science 284: 1372-1376, 1999.

14. Schwarzkopf M, Knobeloch KP, Rohde E, Hinderlich S, Wiechens N, Lucka L, Horak I, Reutter W and Horstkorte R: Sialylation is essential for early development in mice. Proc Natl Acad Sci USA 99: 5267-5270, 2002.

15. Suzuki O, Nozawa Y, Kawaguchi T and Abe M: UDP-GlcNAc2epimerase regulates cell surface sialylation and cell adhesion to extracellular matrix in Burkitt's lymphoma. Int J Oncol 20: 1005-1011, 2002.

16. Goni FM and Alonso A: Biophysics of sphingolipids I. Membrane properties of sphingosine, ceramides and other simple sphingolipids. Biochim Biophys Acta 1758: 1902-1921, 2006.

17. Spiegel S and Milstien S: Sphingosine 1-phosphate, a key cell signaling molecul. J Biol Chem 277: 25851-25854, 2002.

18. Hannun YA and Obeid LM: The ceramide-centric universe of lipid-mediated cell regulation: stress encounters of the lipid kind. J Biol Chem 277: 25847-25850, 2002.

19. Louis AP, ZviF and Richard K: Stress-induced apoptosis and the sphingomyelin pathway. Biochem Pharmacol 53: 615-621, 1997.

20. Cuvillier O: Sphingosine in apoptotic signaling. Biochim Biophys Acta 1585: 153-162, 2002.
21. Tani M, Igarashi Y and Ito M: Involvement of neutral ceramidase in ceramide metabolism at the plasma membrane and in extracellular milieu. J Biol Chem 280: 36592-36600, 2005.

22. Iwata M, Herrington J and Zager RA: Sphingosine: A mediator of acute renal tubular injury and subsequent cytoresistance. Proc Natl Acad Sci USA 92: 8970-8974, 1995.

23. Suzuki O, Nozawa Y and Abe M: Regulatory roles of cell surface sialylation in susceptibility to sphingomyelinase in human diffuse large B cell lymphoma. Int J Oncol 27: 209-214, 2005.

24. Suzuki O, Nozawa Y and Abe M: Regulatory roles of cell surface sialylation in sphingolipid-induced cell death in human B cell lymphoma. Oncol Rep 16: 851-857, 2006.

25. Wang Z, Sun Z, Li AV and Yarema KJ: Roles for UDPGlcNAc2-epimerase/ManNAc 6-kinase outside of sialic acid biosynthesis: modulation of sialyltransferase and Bip expression, GM3 and GD3 biosynthesis, proliferation, and apoptosis, and ERK1/2 phosphorylation. J Biol Chem 281: 27016-27028, 2006.

26. Von Haefen C, Wieder T, Gillissen B, Starck L, Graupner V, Dorken B and Daniel PT: Ceramide induces mitochondrial activation and apoptosis via a Bax-dependent pathway in human carcinoma cells. Oncogene 21: 4009-4019, 2002.

27. Wagenknecht B, Roth W, Gulbins E, Wolburg H and Weller M: $\mathrm{C} 2$-ceramide signaling in glioma cells: synergistic enhancement of CD95-mediated, caspase-dependent apoptosis. Cell Death Differ 8: 595-602, 2001.

28. Hetz CA, Hunn M, Rojas P, Torres V, Leyton L and Quest AF: Caspase-dependent initiation of apoptosis and necrosis by the Fas receptor in lymphoid cells: onset of necrosis is associated with delayed ceramide increase. J Cell Sci 115: 4671-4683, 2002.

29. Xiang J, Chao DT and Korsmeyer SJ: BAX-induced cell death may not require interleukin 1 beta-converting enzyme-like proteases. Proc Natl Acad Sci USA 93: 14559-14563, 1996.

30. Montes LR, Ruiz-Arguello MB, Goni FM and Alonso A: Membrane restructuring via ceramide results in enhanced solute efflux. J Biol Chem 277: 11788-11794, 2002.

31. Burow ME, Weldon CB, Collins-Burow BM, Ramsey N, McKee A, Klippel A, McLachlan JA, Clejan S and Beckman BS: Cross-talk between phosphatidylinositol 3-kinase and sphingomyelinase pathways as a mechanism for cell survival/death decisions. J Biol Chem 275: 9628-9635, 2000.

32. Zundel W, Swiersz LM and Giaccia A: Caveolin 1-mediated regulation of receptor tyrosine kinase-associated phosphatidylinositol 3-kinase activity by ceramide. Mol Cel Biol 20: 1507-1514, 2000.

33. Mehlen P and Puisieux A: Metastasis: a question of life or death. Nat Rev Cancer 6: 449-458, 2006. 